\title{
Assessing the impact of travel restrictions on international spread of the 2014 West African Ebola epidemic
}

Poletto $^{1,2}$, M F Gomes 3 , A Pastore y Piontti ${ }^{3}$, L Rossi ${ }^{4}$, L Bioglio ${ }^{1,2}$, D L Chao5, I M Longini ${ }^{6}$, M E Halloran ${ }^{5}$,

V Colizza (vittoria.colizza@inserm.fr) ${ }^{1,2,4}$, A Vespignani ${ }^{3}$

1. INSERM, UMR-S 1136, Institut Pierre Louis d’Epidémiologie et de Santé Publique, Paris, France

2. Sorbonne Universités, UPMC Univ Paris 06, UMR-S 1136, Institut Pierre Louis d'Epidémiologie et de Santé Publique, Paris, France

3. Laboratory for the Modeling of Biological and Socio-Technical Systems, Northeastern University, Boston, Massachusetts, United States

4. Institute for Scientific Interchange (ISI), Turin, Italy

5. Vaccine and Infectious Disease Division, Fred Hutchinson Cancer Research Center, Seattle, Washington, United States

6. Department of Biostatistics, University of Florida, Gainesville, Florida, United States

Citation style for this article:

Poletto C, Gomes MF, Pastore y Piontti A, Rossi L, Bioglio L, Chao DL, Longini IM, Halloran ME, Colizza V, Vespignani A. Assessing the impact of travel restrictions on international spread of the 2014 West African Ebola epidemic. Euro Surveill. 2014;19(42):pii=20936. Available online: http://www.eurosurveillance.org/

ViewArticle.aspx?Articleld $=20936$

Article submitted on 26 September 2014 / published on 23 October 2014

The quick spread of an Ebola outbreak in West Africa has led a number of countries and airline companies to issue travel bans to the affected areas. Considering data up to 31 Aug 2014, we assess the impact of the resulting traffic reductions with detailed numerical simulations of the international spread of the epidemic. Traffic reductions are shown to delay by only a few weeks the risk that the outbreak extends to new countries.

\section{Introduction}

The 2014 Ebola outbreak currently involves three countries with widespread and intense transmission in the West African region (Guinea, Liberia and Sierra Leone) and four others where initial case(s) or localised transmission have been reported (Nigeria, Senegal, Spain and the United States), reaching a total of 8,997 cases and 4,493 deaths in the official report of 15 October 2014 [1].

With the number of cases exponentially increasing in the affected area, several agencies and governments are calling for massive coordinated interventions aimed at the surveillance and containment of the epidemic [2]. Scaling up the international response appears necessary for providing financial support, supply of technical resources and expertise, and delivery of essential services to the affected area [2]. The need to consider an international framework lies also in the possible further international spread of the epidemic [3]. In response to such concerns and in an attempt to reduce the risk of case importation, several countries and airlines have adopted travel restrictions to and from the affected area. These include the suspension of flights by a number of carriers, air/sea/land border closures, restrictions for non-residents, suspension of visa issuance, and entry screening. Travel bans could potentially hamper the delivery of medical supplies and the deployment of specialised personnel to manage the epidemic [4]. Although international public health and relief agencies and representatives have been urgently calling for lifting such travel bans [4-6], these diseaseavoidance mechanisms remain in place at the time of writing, and more are being considered. In light of their potentially harmful effects, the benefits of travel restrictions need to be carefully evaluated.

Air travel data is a critical source of information that has been recently analysed to characterise the degree of connectivity of the affected area to the rest of the world $[7,8]$. Air travel and human mobility data have also been integrated in large-scale computer microsimulations that, taking explicitly into account the local evolution of the epidemic in the affected countries, quantify the risk for international spread of Ebola virus disease (EVD) out of Africa in the short term [9]. Hypothetical simulation scenarios considering an $80 \%$ reduction of passenger traffic flow out of the region indicate that further international spread is delayed by only a few weeks. Here, we use the model to quantify the effect that the travel restrictions implemented during August 2014 by countries and airlines have on the global spread of Ebola. By comparing the differences between simulations with and without travel restrictions, we can make quantitative estimates of the effectiveness of such restrictions on reducing the importation of new Ebola cases to countries outside of West Africa. Our goal is to inform the debate over the utility of travel bans to slow the spread of Ebola. 
Travel restrictions to and from Ebola-affected areas implemented by authorities and companies as of 31 August 2014

\begin{tabular}{|c|c|c|c|c|}
\hline $\begin{array}{l}\text { Travel-related } \\
\text { measure }\end{array}$ & $\begin{array}{c}\text { Travel-related } \\
\text { measureAuthorities/ } \\
\text { Companies }\end{array}$ & Starting date of intervention ${ }^{a}$ & Target area & Additional details ${ }^{\mathrm{b}, \mathrm{c}}$ \\
\hline \multirow{3}{*}{ Flight suppression } & Three European airlines & From 6 Aug 2014 to 28 Aug 2014 & Liberia Sierra Leone & See SI \\
\hline & Two Asian airlines & From 6 Aug 2014 to 14 Aug 2014 & Guinea Kenya & See SI \\
\hline & Six African airlines & From 6 Aug 2014 to 26 Aug 2014 & $\begin{array}{c}\text { Guinea Liberia Nigeria } \\
\text { Sierra Leone }\end{array}$ & See SI \\
\hline \multirow{19}{*}{$\begin{array}{l}\text { Travel ban and/or } \\
\text { border closure }\end{array}$} & Ghana & 1 Aug 2014 & $\begin{array}{c}\text { Liberia Nigeria } \\
\text { Sierra Leone } \\
\end{array}$ & $\begin{array}{l}\text { Ban of all flights from the } \\
\text { affected countries }\end{array}$ \\
\hline & Zambia & 8 Aug 2014 & $\begin{array}{l}\text { Liberia Nigeria } \\
\text { Sierra Leone }\end{array}$ & $\begin{array}{c}\text { Ban on entry for citizens of } \\
\text { the target countries }\end{array}$ \\
\hline & Mauritania & 11 Aug 2014 & $\begin{array}{l}\text { Liberia Nigeria } \\
\text { Sierra Leone }\end{array}$ & $\begin{array}{c}\text { Ban on entry for citizens of } \\
\text { the target countries }\end{array}$ \\
\hline & Chad & 11 Aug 2014 & $\begin{array}{l}\text { Liberia } \\
\text { Sierra Leone }\end{array}$ & Ban of all flights \\
\hline & Cote D'Ivoire & 13 Aug 2014 & Nigeria & $\begin{array}{c}\text { Ban of all flights, closure of } \\
\text { land borders }\end{array}$ \\
\hline & Nigeria & 13 Aug 2014 & $\begin{array}{l}\text { Guinea Liberia } \\
\text { Sierra Leone }\end{array}$ & $\begin{array}{l}\text { Ban of all flights from the } \\
\text { affected countries }\end{array}$ \\
\hline & Botswana & 14 Aug 2014 & $\begin{array}{l}\text { Guinea Liberia } \\
\text { Sierra Leone }\end{array}$ & $\begin{array}{l}\text { Banned travellers from } \\
\text { affected countries }\end{array}$ \\
\hline & Equatorial Guinea & 15 Aug 2014 & $\begin{array}{l}\text { Guinea Liberia } \\
\text { Sierra Leone }\end{array}$ & $\begin{array}{c}\text { Suspended the issuance } \\
\text { of visas }\end{array}$ \\
\hline & Gambia & 15 Aug 2014 & $\begin{array}{l}\text { Guinea Liberia } \\
\text { Sierra Leone }\end{array}$ & Ban of all flights \\
\hline & Kenya & 16 Aug 2014 & $\begin{array}{l}\text { Guinea Liberia } \\
\text { Sierra Leone }\end{array}$ & Ban of all flights \\
\hline & Cape Verde Islands & 19 Aug 2014 & $\begin{array}{l}\text { Guinea Liberia } \\
\text { Sierra Leone }\end{array}$ & Border closure \\
\hline & South Africa & 21 Aug 2014 & $\begin{array}{l}\text { Guinea Liberia } \\
\text { Sierra Leone }\end{array}$ & $\begin{array}{c}\text { Ban on entry for citizens of } \\
\text { target countries }\end{array}$ \\
\hline & Cameroon & 21 Aug 2014 & $\begin{array}{l}\text { Guinea Liberia } \\
\text { Sierra Leone }\end{array}$ & Border closure \\
\hline & Senegal & 21 Aug 2014 & $\begin{array}{l}\text { Guinea Liberia } \\
\text { Sierra Leone }\end{array}$ & Closure of land borders \\
\hline & Rwanda & 24 Aug 2014 & $\begin{array}{l}\text { Guinea Liberia } \\
\text { Sierra Leone }\end{array}$ & Border closure \\
\hline & Gabon & 26 Aug 2014 & $\begin{array}{l}\text { Guinea Liberia } \\
\text { Sierra Leone }\end{array}$ & Border closure \\
\hline & Namibia & 26 Aug 2014 & $\begin{array}{l}\text { Guinea Liberia } \\
\text { Sierra Leone }\end{array}$ & Border closure \\
\hline & Guinea Bissau & Before 26 Aug 2014 & $\begin{array}{l}\text { Guinea Liberia } \\
\text { Sierra Leone }\end{array}$ & $\begin{array}{l}\text { Ban of all flights, closure of } \\
\text { land borders }\end{array}$ \\
\hline & Togo & Before 26 Aug 2014 & $\begin{array}{l}\text { Guinea Liberia } \\
\text { Sierra Leone }\end{array}$ & Ban of all flights \\
\hline
\end{tabular}

SI: supplementary information.

a Depending on the information available, this can be either the date of intervention or the date of the bulletin/news.

b Closure of land borders is for all travellers irrespective of citizenship.

c Border closure is generally for citizens of the target countries and travellers coming from the affected area, with the exception of nationals of the destination country.

The list is obtained from publicly available sources extracted from the search ["ebola" AND "travel"] on Twitter on 1 September 2014. Additional searches of news published on the Internet were performed to confirm and complement the initial list. More detailed information and references are provided in the supplementary information* available at http://www.mobs-lab.org/ebola-eurosurvsup.html 
Modelled effect of travel restrictions on the risk of Ebola case importation for individual countries

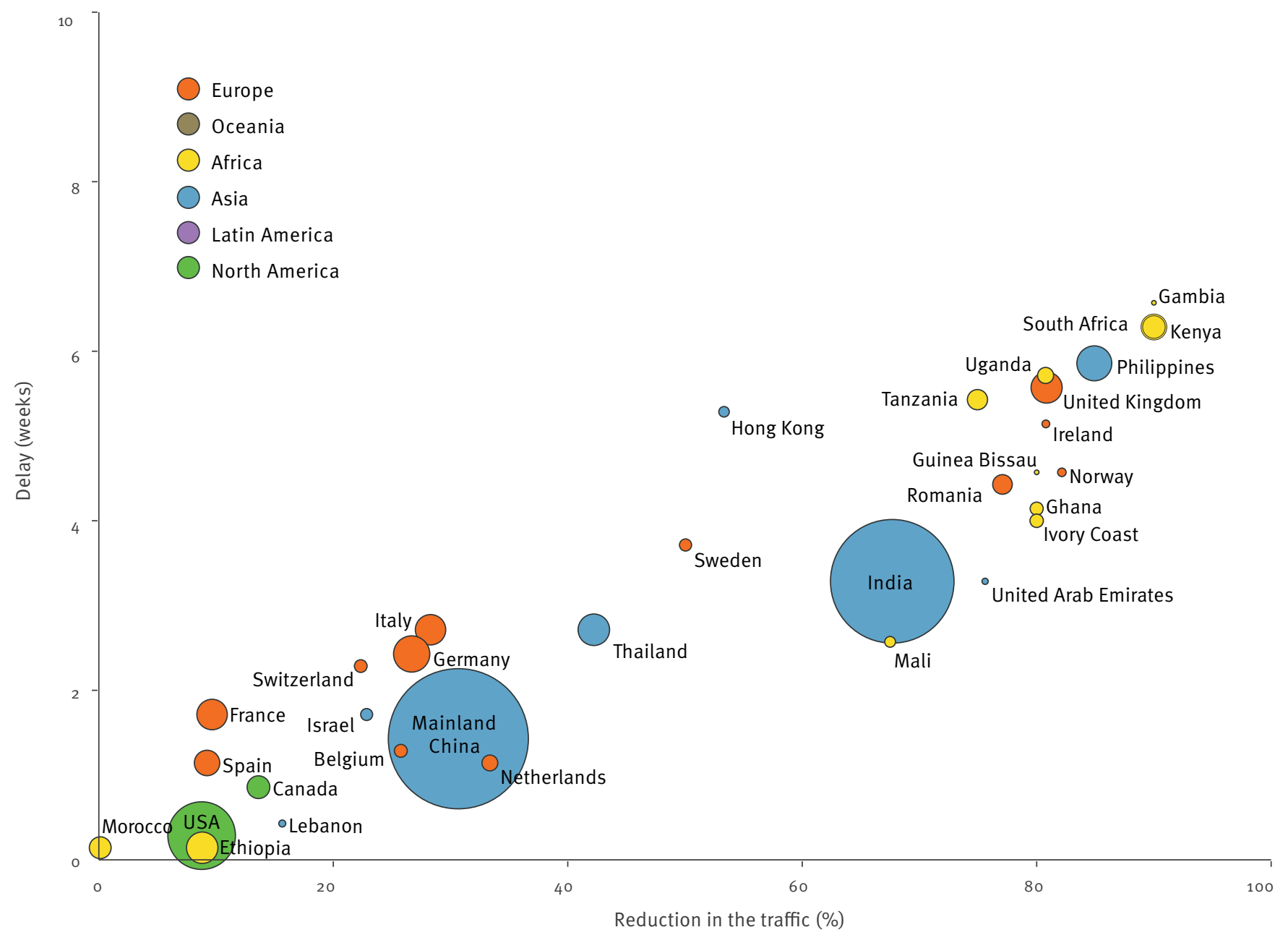

The delay in the risk of case importation induced by the applied travel restrictions is shown for each country versus the overall reduction of the country's air traffic. The delay was calculated as the time after which the risk of case importation in the scenario with travel restrictions was equal to the value reached on 30 September 2014 in the baseline case. For clarity, only countries having a non-negligible risk of importation $(>0.5 \%)$ are shown in the plot. The size of the dots is proportional to the country's population. Colours indicate the continents.

\section{Methods}

We used 2013 flight itinerary data providing travel volumes of passengers flying between any origindestination pair of commercial airports in the world (International Air Transport Association (IATA), www. iata.org; Official Airline Guide (OAG), www.oag.com). Starting from the airport of origin, each itinerary reports all connecting airports to reach the final destination and the airline companies handling the connecting flights along the given route. We collected publicly available information on the travel restrictions related to Ebola-affected regions up to 31 August 2014. We considered both travel bans implemented by national authorities and flight discontinuations by individual airlines (Table). Restrictions are heterogeneous in terms of start date and target country in the affected area (e.g. some concern the entire Western Africa area and others just one of its countries). Flight suspensions by airline company $A$ targeting the set of countries $C$ were considered by removing from the flight database all itineraries (and associated travel volumes) to $C$ where $A$ was the dominant airline. Then, travel bans and border closures implemented by country $B$ targeting the set of countries $C$ were considered by singling out all itineraries connecting $B$ with $C$ (in both directions) and reducing by a factor $r$ the associated travel volumes, with $r_{\text {neighbours }}=80 \%$ for the affected area's neighbouring countries and $r_{\text {others }}=90 \%$ for all other countries, to model residual human mobility and non-compliance to policies. The resulting overall traffic reduction for each country was obtained by combining the effect of flight discontinuation and country level travel bans. We further required that the overall reduction could not be larger than $r$. This additional constraint is meant to model additional types of possible movements not captured by the air travel data (e.g. cross-border ground movement) and also adaptation to the restrictions (e.g. rearrangements of flight itineraries to other airline companies) for which detailed data are not currently available. 


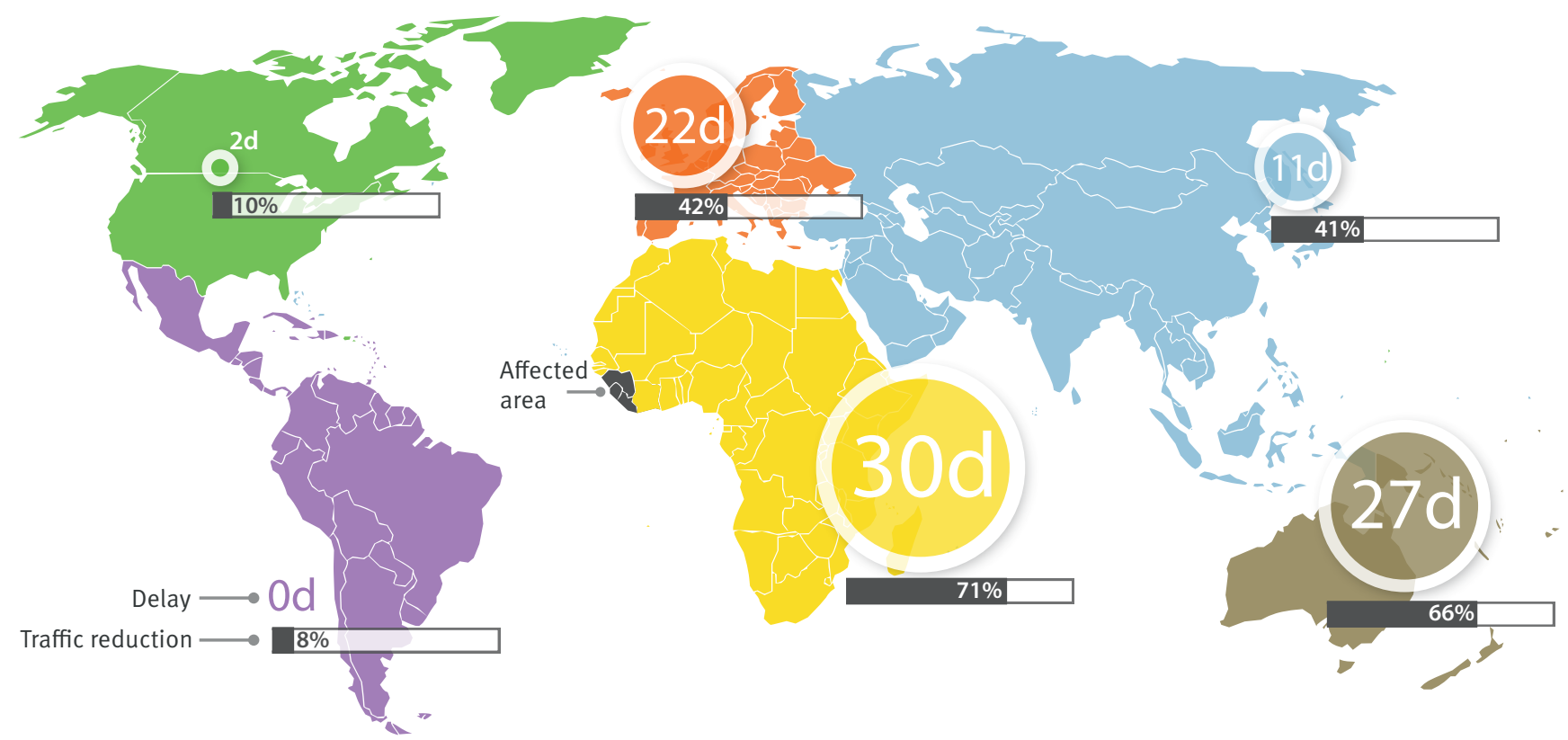

Grey bars below the circles indicate the overall travel reduction per continent resulting from the currently applied travel restrictions. The size of the discs is related to the duration of the delay.

We used the Global Epidemic and Mobility model $[10,11]$ applied to the EVD outbreak [9] to simulate case importation events in 220 countries around the world. The model [9] accounts for EVD transmission in the general community, in hospital settings, and during funeral rites [12]. Basic reproductive numbers for each of these settings were inferred through a Monte Carlo likelihood analysis considering more than 3,500,000 simulations that sampled the disease model parameter space and the case data on the EVD outbreak up to 27 August 2014. Other epidemiological parameters were taken from the literature $[9,12,13]$. The spatio-temporal epidemic evolution is modelled using individuallevel dynamics where transitions are mathematically defined by chain binomial and multinomial processes to preserve the discrete and stochastic nature of the processes. Individuals in the latent state are allowed to follow the same mobility patterns and international travel behaviour as those who are not infected. Travel probabilities are calculated based on the integrated flight database and mechanistically simulated travel and commuting patterns. More details on the model and on the parameters' inference procedure are provided in [9] and in the supplementary information* (http://www.mobs-lab.org/ebola-eurosurvsup.html).

To assess the effect of current travel restrictions on the risk of case importation, we compared the international spread of the EVD epidemic obtained from numerical simulations of the model with and without the travel reductions. We focus on short-term projections and calculate the probability of case importation per country (and per continent) predicted for 30 September 2014 in the baseline scenario without travel restrictions. The probability of importation at that date is still relatively small for most of the countries and detailed values for different dates can be found in [9]. We then compute the time delay needed to reach the same value of case importation probability per country (or continent) once the travel restrictions shown in the Table are implemented.

\section{Results}

The modelled travel restrictions impacted airline passenger volume to countries worldwide in a very heterogeneous manner (Figure 1, reporting results for countries with a case importation probability larger than $0.5 \%$ as of 30 September 2014). Notably, flight suppressions and border closures did not affect solely the countries implementing such measures but they also had considerable repercussions on others (e.g. India and the Philippines following the suppression of Emirates Airline flights). With few exceptions, African countries were predicted to experience traffic reductions greater than $70 \%$ due to generalised travel bans.

The total estimated reduction of $60 \%$ of airline passenger traffic connecting the West Africa region currently most affected by Ebola to the rest of the world was shown to be insufficient to prevent the exportation of Ebola cases. The observed traffic reductions were shown to delay the risk of case importation per country 
from a few days to a few weeks (Figure 1). The majority of the countries ( $56 \%$, mainly in Central Europe, Asia and the Americas) would not experience a delay longer than one month. At the continental level, the delay was predicted to be negligible for the Americas, and at most one month for the African continent (Figure 2). Results confirmed previous empirical evidence from past epidemics of other infectious diseases and were in agreement with mathematical modelling studies of the relationship between the exponential growth rate of an epidemic in a source region and the exportation to other regions [14-18]. Those can be summarised with the simple rule of thumb that a $50 \%$ travel reduction produces a delay equal to the doubling time of the number of cases.

\section{Discussion}

Although the current travel restrictions postpone the spread of EVD to other continents by at most a few weeks, they can impose heavy logistical constraints on the management of the epidemic in the countries severely hit by the disease and ill-equipped to cope with its alarming rapid spread [4-6]. If not offset by massive humanitarian operations, they can cause major shortages of food, energy and essential resources, with the potential to severely compromise local economies [19].

Similar to what happened during the severe acute respiratory syndrome (SARS) outbreak in 2003 [20], adverse effects on local economies of the same countries implementing the bans may also occur, as a reduced connectivity and the increased apprehension may induce a considerable reduction in the demand for service industries (business travel, tourism and associated services).

International agencies suggest that currently unaffected countries should invest in health system preparedness, strengthening their own capacity to detect and contain newly imported cases [21]. These measures are expected to substantially reduce the risk of importation. Indeed, while the relatively long latency period of EVD may allow exposed individuals to travel long distances, infectiousness occurs at symptom onset only, so that potentially infectious individuals can be clinically recognised. The mode of transmission is expected to minimise the risk of spread during a flight [21].

It is also worth mentioning that delays in the global spread of the outbreak may have to be evaluated with respect to the development timeline of pharmaceutical interventions. For instance, Ebola vaccines are being fast-tracked, and field trials are planned, probably in healthcare workers at high risk of exposure to the virus in the affected areas [22].

The results presented here need to be considered in light of the assumptions and limitations of the modelling approach used. We considered all travel restrictions obtained from publicly available sources that were implemented up to the end of August 2014, but this list may not be complete and not all information could be verified with the original sources. In the presence of uncertainty (e.g. vague information or inconsistency between different news) we assumed the scenario with the strongest traffic reduction in order to provide the best-case scenario in terms of resulting delay. An additional world-wide fear-induced decrease of tourist and business travel to the region has been observed $[23,24]$ in September and has probably further increased the delay in case importation, although only logarithmically with the magnitude of the traffic reduction $[15,16]$.

The simulation presented was based on the study of the current West African outbreak described in Gomes et al. [9], which contains estimates of the incubation period and generation time based on past Ebola outbreaks. Recent estimates for the current outbreak have been published by Hollingsworth et al., and Althaus et al. $[13,25]$. Updated results on the risk of the epidemic spread are regularly posted on our website http:// www.mobs-lab.org/ebola.html to account for the most recently published epidemiological information. We note that, although these parameters affect the absolute value of the probability of importation, they do not affect the relative delay depending on the epidemic growth rate $[15,16]$.

Detailed data on unmeasured movements during the epidemic and on possible rearrangements of air travel volumes following decisions of airline companies to suspend flights are not available to be implemented directly into the model. For this reason, we took these aspects into account by considering a maximum of $90 \%$ overall traffic reduction $(80 \%$ for countries bordering the currently affected area), representing the maximum ability of a country to implement the border closures. A sensitivity analysis exploring smaller values of these upper bounds $(70 \%$ for neighbouring countries and $80 \%$ for the others) yielded delays in the risk of case importations reduced to five weeks for the African countries with the largest overall reductions (supplementary information*).

\section{Conclusion}

This study indicates that travel bans are only delaying the further international spread of the Ebola outbreak in West Africa for a limited time, at the risk of compromising connectivity to the region, mobilisation of resources to the affected area and sustained response operations, all actions of critical value for the immediate local control of EVD and for preventing its further geographical spread. Any decision making process on this issue must take into account complex cost-benefit analyses of travel bans.

${ }^{*}$ Note

Supplementary information made available by the authors on an independent website is not edited by Eurosurveillance, and Eurosurveillance is not responsible for the content. The 
material can be accessed at: http://www.mobs-lab.org/ebola-eurosurvsup.html

\section{Acknowledgements}

This work has been partially supported by the EC-Health contract no. 278433 (PREDEMICS) and the ANR contract no. ANR- 12-MONU-0018 (HARMSFLU). We acknowledge also funding from DTRA-1-0910039 and MIDAS-National Institute of General Medical Sciences U54GM111274. The funders had no role in study design, data collection and analysis, decision to publish, or preparation of the manuscript.

\section{Conflict of interest}

None declared.

\section{Authors' contributions}

CP, VC, MG, AP, AV provided the data. CP, LR performed the computational experiments. CP VC AV conceived and designed the study. All authors discussed the results, edited and commented the manuscript draft. All authors read and approved the final manuscript.

\section{References}

1. World Health Organization (WHO). WHO: Ebola response roadmap situation report. Geneva: WHO; 15 October 2014. Available from: http://apps.who.int/iris/ bitstream/10665/136508/1/roadmapsitrep150ct2014.pdf?ua=1

2. World Health Organization (WHO). Ebola response roadmap. Geneva: WHO; 28 August 2014. Available from: http://apps.who.int/iris/bitstream/10665/131596/1/ EbolaResponseRoadmap.pdf?ua=1

3. World Health Organization (WHO). WHO Statement on the meeting of the International Health Regulations Emergency Committee regarding the 2014 Ebola outbreak in West Africa. Geneva: WHO; 8 August 2014. Available from: http://www.who. int/mediacentre/news/statements/2014/ebola-20140808/en/

4. World Health Organization (WHO). UN senior leaders outline needs for global Ebola response. Geneva: WHO; 3 September 2014. Available from: http://www.who.int/mediacentre/news/ releases/2014/ebola-response-needs/en/

5. United Nations (UN) News Center. Interview with David Nabarro, UN System Coordinator on Ebola. NewYork: UN; 21 August 2014. Available from: http://www.un.org/apps/news/ newsmakers.asp?NewsID=109

6. African Union's executive council urges lifting of travel restrictions related to Ebola outbreak. Addis Ababa: African union; 16 September 2014. Available from: http://pages.au.int/ ebola/news/african-union\%E2\%80\%99s-executive-councilurges-lifting-travel-restrictions-related-ebola-outbrea

7. The Disease Daily. Ebola 2014: a rapid threat assessment. HealthMap; 5 August 2014. Available from: http://healthmap.org/site/diseasedaily/article/ ebola-2014-rapid-threat-assessment- 8514

8. Brockmann D, Shaade L, Verbeek L. 2014 Ebola outbreak: worldwide air-transportation, relative import risk and most probable spreading routes. Berlin: Robert Koch institute; 4 August 2014. Available from: http://rocs.hu-berlin.de/projects/ ebola/

9. Gomes MFC, Pastore y Piontti A, Rossi L, Chao D, Longini I, Halloran ME, et al. Assessing the international spreading risk associated with the 2014 West African Ebola outbreak. PLoS Curr. 2014;1:pii= pii: ecurrents. outbreaks. cd818f63d40e24aef769dda7dfgeoda5. http://dx.doi.org/10.1371/currents.outbreaks. cd818f63d40e24aef769dda7df9eoda5

10. Balcan D, Hu H, Goncalves B, Bajardi P, Poletto C, Ramasco JJ, et al. Seasonal transmission potential and activity peaks of the new influenza $\mathrm{A}\left(\mathrm{H}_{1} \mathrm{~N}_{1}\right)$ : a Monte Carlo likelihood analysis based on human mobility. BMC Med. 2009;7(1):45. http://dx.doi. org/10.1186/1741-7015-7-45 PMID:19744314

11. Balcan D, Colizza V, Gonçalves B, Hu H, Ramasco JJ, Vespignani A. Multiscale mobility networks and the spatial spreading of infectious diseases. Proc Natl Acad Sci USA. 2009;106(51):21484-9. http://dx.doi.org/10.1073/ pnas.0906910106 PMID:20018697

12. Legrand J, Grais RF, Boelle PY, Valleron AJ, Flahault A. Understanding the dynamics of Ebola epidemics. Epidemiol Infect. 2007;135(4):610-21. http://dx.doi.org/10.1017/ So950268806007217 PMID:16999875

13. WHO Ebola Response Team. Ebola virus disease in West Africa-the first 9 months of the epidemic and forward projections. $\mathrm{N}$ Engl J Med. 2014;371(16):1481-95. http://dx.doi.org/10.1056/ NEJMoa1411100 PMID:25244186

14. Hollingsworth TD, Ferguson NM, Anderson RM. Will travel restrictions control the international spread of pandemic influenza? Nat Med. 2006;12(5):497-9. http://dx.doi. org/10.1038/nmo506-497 PMID:16675989

15. Scalia Tomba G, Wallinga J. A simple explanation for the low impact of border control as a countermeasure to the spread of an infectious disease. Math Biosci. 2008;214(1-2):70-2. http:// dx.doi.org/10.1016/j.mbs.2008.02.009 PMID:18387639

16. Gautreau A, Barrat A, Barthélemy M. Global disease spread: statistics and estimation of arrival times. J Theor Biol. 2008;251(3):509-22. http://dx.doi.org/10.1016/j. itbi.2007.12.001 PMID:18222486

17. Cowling BJ, Lau LL, Wu P, Wong HW, Fang VJ, Riley S, et al. Entry screening to delay local transmission of 2009 pandemic influenza $A\left(\mathrm{H}_{1} \mathrm{~N}_{1}\right)$. BMC Infect Dis. 2010;10(1):82. http:// dx.doi.org/10.1186/1471-2334-10-82 PMID:20353566

18. Bajardi P, Poletto C, Ramasco JJ, Tizzoni M, Colizza V, Vespignani A. Human mobility networks, travel restrictions, and the global spread of $2009 \mathrm{H}_{1} \mathrm{~N}_{1}$ pandemic. PLoS ONE. 2011;6(1):e16591. http://dx.doi.org/10.1371/journal. pone.0016591 PMID:21304943

19. Reuters. Ebola threatens food security in West Africa: FAO. 2 September 2014. Available from: http://www.reuters.com/article/2014/09/02/ us-health-ebola-food-idUSKBNoGXoHB20140902

20. Lee J-W, McGibbin WJ. Estimating the global economic costs of SARS. In Learning from SARS: Preparing for the next disease outbreak: workshop summary. Institute of Medicine (US) Forum on Microbial Threats; Knobler S, Mahmoud A, Lemon S, et al., editors. Washington (DC): National Academies Press (US); 2004 .

21. World Health Organization (WHO). Travel and transport risk assessment: interim guidance for public health authorities and the transport sector. Geneva: WHO; September 2014. Available from: http://apps.who.int/iris/bitstream/10665/132168/1/ WHO_EVD_Guidance_TravelTransportRisk_14.1_eng. pdf?ua $=1 \&$ ua $=1 \% 20$

22. World Health Organization (WHO). Media center. Experimental Ebola vaccines. Geneva; WHO. [Accessed: 17 October 2014. Available from: http://www.who.int/mediacentre/news/ ebola/01-october-2014/en/index1.html

23. International Monetary Fund Survey Magazine. Affected countries working on post-Ebola recovery plan. Washington, DC: International Monetary Fund; 11 October 2014. Available from: http://www.imf.org/external/pubs/ft/survey/so/2014/ CAR101114B.htm

24. World Bank. 2014. The economic impact of the 2014 Ebola epidemic : short and medium term estimates for West Africa. Washington, DC : The World Bank.[Accessed: 17 October 2014]. Available from: http://documents.worldbank.org/curated/ en/2014/10/20270083/economic-impact-2014-ebola-epidemicshort-medium-term-estimates-west-africa

25. Althaus CL. Estimating the Reproduction Number of Ebola Virus (EBOV) During the 2014 Outbreak in West Africa. PLOS Currents Outbreaks. 2014. doi: 10.1371/currents.outbreaks.91afb5eof 27 ge7f29e7056095255b288. 